\title{
Anatomic feasibility of stenting type A aortic dissection: Paving the way for the future
}

\author{
Davide Pacini, MD, PhD, Giacomo Murana, MD, and Luca Di Marco, MD, PhD
}

\author{
From the Cardiac Surgery Unit, Cardio-Thoraco-Vascular Department, S. Orsola Hospital, University of Bologna, \\ Bologna, Italy. \\ Disclosures: Authors have nothing to disclose with regard to commercial support. \\ Received for publication June 4, 2018; revisions received June 4, 2018; accepted for publication June 5, 2018; \\ available ahead of print July 17, 2018 \\ Address for reprints: Davide Pacini, MD, PhD, Cardiac Surgery Unit, Cardio-Thoraco-Vascular Department, S. \\ Orsola Hospital, University of Bologna, Bologna, Italy (E-mail: davide.pacini@unibo.it). \\ J Thorac Cardiovasc Surg 2019;157:35-6 \\ $0022-5223 / \$ 36.00$ \\ Copyright (c) 2018 by The American Association for Thoracic Surgery \\ https://doi.org/10.1016/j.jtcvs.2018.06.007
}

The first successful surgical repair of a type A aortic dissection was reported by DeBakey and colleagues ${ }^{1}$ in 1954 . Previously only palliative surgical solutions had been described. DeBakey himself wrote that "treatment has been almost entirely symptomatic and unsatisfactory, and the few previous efforts to attack the problem surgically have all proved unsuccessful." 1

Just few years later, DeBakey and colleagues ${ }^{2}$ reported a series of 72 patients with dissecting aneurysm of the aorta treated with aortic resection that resulted in a respectable $26 \%$ operative mortality. The key was to tailor the surgical procedure depending on the location and extent of the lesion, according to the anatomic variability of the thoracic and thoracoabdominal aorta. Afterwards, such a remarkable approach was translated in 2 simple classificationsfamiliar to all of us - that paved the way for the modern surgical approach. . $^{2,3}$

In the current endovascular era, the possibility to treat acute type A aortic dissection with stent grafts repeats the previous historical scenario in which preoperative anatomic considerations became mainstream for the success of the procedure.

Hence, in this issue of the Journal, Kreibich and colleagues ${ }^{4}$ achieved this goal by looking at the anatomic feasibility of thoracic endovascular aortic repair in potential candidates with acute type A aortic dissection. The authors bring to our attention an assembled endovascular valved conduit that is able to simultaneously address the aortic valve (with a transcatheter prosthesis) and the ascending aorta (with a stent graft) in cases of aortic dissection with root involvement. And... how revealing!

The objective of the study was to screen patients with acute type A aortic dissection for the anatomic feasibility of this experimental device. The authors used high-quality computed tomography scans in 167 patients where they simulated stent graft 10-mm long landing zones (LZ) starting at the sinotubular junction (proximal LZ) and ending at the brachiocephalic trunk (distal LZ). In two-thirds $(68 \%$ )

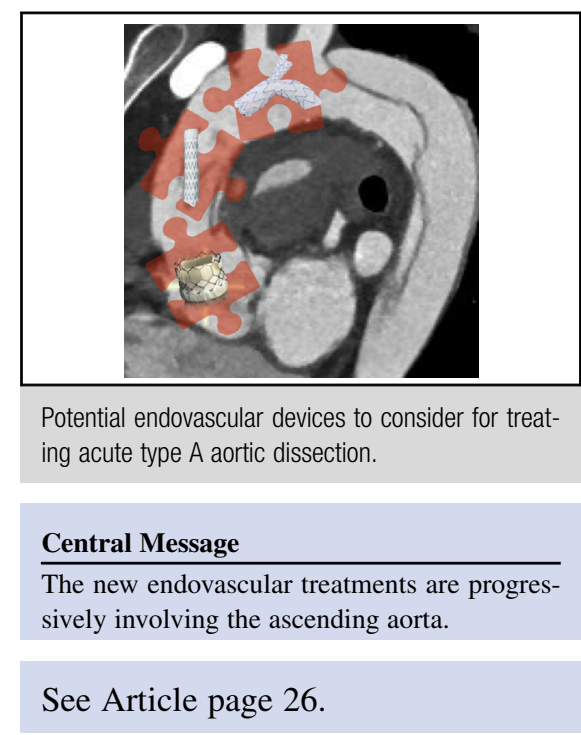

of all patients, the study revealed an entry tear in a coverable zone of the ascending aorta with sufficient proximal and distal LZ. Of course, the new valve-carrying conduit had to face the great variability of aortic dissection represented by the distorted anatomy of the thoracic aorta, the characteristics of the entry tears, the presence of coronary arteries, and the extreme fragility of the aortic wall.

Indeed, the authors were conscious of these limitations. Therefore, according to the location of the primary entry tear and condition of the patient, they propose it as a temporary treatment solution (eg, in case of malperfusion and entry in the aortic arch or the descending aorta) or a (semi-) permanent solution (in case of an entry tear in a coverable zone). ${ }^{4}$ In any case, the valve conduit could close any entry in the ascending aorta, initiate true lumen expansion and thereby treat malperfusion, treat or prevent aortic regurgitation, drain any pericardial effusion, and stabilize the ascending aorta. ${ }^{4}$ Perhaps these initial considerations highlighted as the treatment of this aortic acute pathology will remain in the surgical domain not just to immediately address periprocedural complications but also to ensure later open surgical treatment when needed.

Based on the findings of this study, we argue that the authors found a way to have their cake and eat it, too. First, they emphasize that many patients could benefit from an endovascular treatment for acute type A dissection. Furthermore, they enforce and pave the way for a new, revolutionary solution. 


\section{References}

1. DeBakey ME, Cooley DA, Creech O Jr. Surgical considerations of dissecting aneurysm of the aorta. Ann Surg. 1955;142:586-612.

2. DeBakey ME, Henly WS, Cooley DA, Crawford ES, Morris GC. Surgical treatment of dissecting aneurysm of the aorta. Analysis of seventy-two cases. Circulation. 1961;24:290-303.
3. Daily PO, Trueblood HW, Stinson EB, Wuerflein RD, Shumway NE. Management of acute aortic dissections. Ann Thorac Surg. 1970;10:237-47.

4. Kreibich M, Soekeland T, Beyersdorf F, Bavaria JE, Schröfel H, Czerny M, et al. Anatomic feasibility of an endovascular valve-carrying conduit for the treatment of type A aortic dissection. J Thorac Cardiovasc Surg. 2019; 157:26-34. 